\title{
EFL LEARNERS' SATISFACTION WITH THE ONLINE LEARNING PROGRAM, TELL ME MORE
}

\author{
George GYAMFI \\ Faculty OF Liberal Arts \\ Prince of Songkla University \\ Hat Yai, Thailand \\ Dr. Panida SUKSEEMUANG \\ Faculty of Liberal Arts \\ Prince of Songkla University \\ Hat Yai, Thailand
}

\section{ABSTRACT}

This study investigated EFL learners' satisfaction with the asynchronous online learning program Tell Me More (TMM). 340 EFL learners' satisfaction with the TMM program was surveyed. In addition, a semi-structured focus group interview was conducted with 10 of the participants to gain in-depth insight into their satisfaction. The findings showed that the learners' were highly satisfied with the vocabulary, reading and listening aspects of the program. It further indicated learners' satisfaction to use TMM for self-study, meaningful content and its language learning potential. Moving forward, in selecting tutorial CALL programs, stakeholders could consider programs with contents that can be adapted to cater for learners' needs and preferences. Additionally, TMM could be improved to include aspects that will help learners develop spontaneous communication skills that will appeal most to learners' interest. Furthermore, CALL programmers are enlightened on aspects in online learning programs that does not only satisfy EFL learners the most but also aspects that needs to be improved to ensure maximum satisfaction. Further research could consider how learners' perceptions influence their satisfaction and how it translates to overall learners' achievement.

Keywords: Learners' satisfaction, Tell Me More, asynchronous online learning program, EFL learners.

\section{INTRODUCTION}

The description of students as "digital natives" (Prensky, 2001) in this century has led to the use of various technologies in innovative ways. This gives students opportunities to improve their English proficiency for real life communication (Warschuaer \& Liaw, 2011). Higher institutions have purchased specific online language learning resources driven by their perception of the importance of the activities in the resource and the weaknesses of students.

Tell Me More (TMM) is one of the advanced self-learning language learning programs. Tell Me More seeks to tutor learners comprehensively by exposing them to over 850 hours of learning content, exercises and different varieties of tasks ranging from vocabulary, grammar, writing, pronunciation, listening and speaking. The content of the online learning platform is structured around authentic events such as at the airport, weather forecast, a linguistic function and a guided listening and speaking dialogue based on scenarios of communication (Rodinadze \& Zarbazoia, 2012). It also have standard activities of interaction, pronunciation, vocabulary and grammar (crossword puzzles, dictation). In sum, TMM asynchronous online language-learning program offers learners the chance to 
self-pace and actively participate in their own learning, giving them the opportunity to personally reflect on their self-learning progress and outcomes.

Institutions professionally equip instructors or educators to ensure the proper implementation of these technologies (Willis, 2006). Warschuaer and liaw (2011) further asserts that administrators buy these high packaged soft wares to provide contents that are near native and realistic as possible, have diverse learning activities, provide a language learning curriculum, assess the needs of learners, equip learners with practical skills and pace out learning.

However, learners have been frequently overwhelmed with learning through different technologies. Due to this, they adapt their learning styles, interests and preferences to utilize new forms of technology to get instant, continuous and effective interaction. They sometimes shown reluctance, low level of motivation and dissatisfaction when they learn with technology. Some even feel disappointed and give up after their initial use of computer learning programs. Research on computer assisted language learning indicates that learners' satisfaction is one of the major determinants for the successful implementation of autonomous online learning (Bodnar et. al, 2016 \& Estelami, 2012).

In rising to the challenge of investigating learners' satisfaction with online learning programs, researchers have resorted to various approaches. For example Arbaugh and Duray, (2002) and Chen and Bagakas, (2003) posited that several factors could account for learners' satisfaction. They categorized these into six factors. These include technology, student, course, system design, teacher and environmental factors. Huang \& Wang, (2012) also stated that learners tend to be satisfied when their expectations of the learning environment, design of a course, teaching practices and learner achievement are met. Even though the dimensions of these researchers are practical, other factors that account for learners' satisfaction need consideration. Factors such as language learning potential, learner fit, meaning focus, authenticity, positive impact and practicality of assessing language course wares also account for learners' satisfaction (Chapelle, Jamieson \& Preiss, 2005). Ignoring these factors may make the implementation and use of technology in language learning challenging and to some extent almost impossible.

Hence, from a descriptive and reflective dimension, this study investigates other critical factors that account for learners' satisfaction with language learning programs. This dimension is taken because, previous studies have either focused on learners' perceptions and the effectiveness of computer learning programs from only a descriptive point of view. These research focus does not capture specific factors that account for learners' satisfaction with computer learning programs. The perspective of this study will therefore give a different viewpoint on what goes into the successful implementation and use of computer programs for language learning. For language learning instructors, the findings will help overcome challenges to ensure the effective utilization of computer learning programs to cater for the needs and preferences of learners. For computer program developers, the study will deepen their knowledge of factors influencing learners' satisfaction with the program and aspects of that need improvement. Overall, an analysis of learners' satisfaction with online learning programs will lead to improvement in online learning practices and learning outcomes. The study could serve as the basis for further research in the field of computer assisted language learning.

Against this background, the subsequent sections describe Tell Me More, followed by literature reviews on asynchronous online learning programs, Tell Me More, learner satisfaction and factors influencing learners' satisfaction with online learning. The mixed methodological approach in the forms of a survey and focus group interview that were utilized in this study will be described and the findings will be finally presented and discussed. 


\section{LITERATURE REVIEW}

\section{Asynchronous Online Learning Programs}

Instructional design of online learning courses has seen a shift to the interactionist approach which emphasizes interaction, meaning negotiation and broad exposure to content (Gass \& Markey, 2007). In a computer mediated environment, this approach focuses on facilitation the acquisition of language through learners' interaction with computer programs to negotiate meaning (Hubbard \& Levy, 2016). This has been the basis for developing synchronous and asynchronous online learning programs. Asynchronous online learning happens when students take instructions from and complete tasks in learning programs that are not delivered in real time or by a person. This theoretical understanding posits the need for learners to engage in not only the interaction of meaning but also its modification. However, only few studies have reported that the modification and interaction through asynchronous online language learning program are beneficial ( $\mathrm{Er}$ et al., 2009; Harris et al., 2009). Other have also investigated the process of interactional adjustment in an online learning environment and have provided insight into other factors that needs to be researched. For example, Kramsch, (2009) and Parlak \& Ziegler, (2017) studies on synchronous and asynchronous internet communication between American learners of French and French learners of English cautioned that not all internet communication has positive outcomes and promote positive perceptions. This finding implies that there may be certain features in online learning programs that may enhance satisfaction or cause dissatisfaction among users.

Norton and William (2012) research on the effectiveness of Egranary (an offline digital library with $750 \mathrm{gb}$ hard drive with specialized browsing software) revealed users satisfaction in terms of how they could change their roles from trainee to trainers. This, improved their literacy skills and knowledge while on and off the program. They indicated that they could adapt outside materials to support learning with the program. In examining how instant messaging shaped learners perceptions, Lewis and Fabos (2005) as cited in Chang, Y.C (2011) stated that the instant messaging (IM) enhanced their social relationships and statuses in diverse contexts as learners found it beneficial in different ways such as sometimes assuming alternative roles. These studies provide insight on how several factors could lead to learner satisfaction and positive perceptions about a learning technology.

\section{Learner Satisfaction}

Learner satisfaction refers to attitudes, perceptions and expectation of learners toward a specific mode of learning ( $\mathrm{Wu}$ et. al, 2010). The term has also been defined as the relationship between learners' expectation and actual gains (Rashidi \& Moghadam, 2014). Researchers have stated that learners tend to be satisfied when their expectations of the learning environment, design of a course, teaching practices and learner achievement are met (Huang \& Wang,2012). After an extensive review, the literature showed the factors might be unending (Wu et al. 2010; Huang \& Wang, 2012). Hence, in this study learners' satisfaction was defined according to Chapelle (2001) principles for evaluating computer assisted language learning (CALL) programs. Chapelle (2001) posited that factors such as language learning potential, learner fit, meaning focus, authenticity, positive impact and practicality are useful for assessing language courseware. In the same vein, these principles could be used to analyze learners' satisfaction with a computer learning program. The evaluative principles denotes that learners' satisfaction with language learning programs may be influenced by its fulfillment of the CALL evaluation principles mentioned above and explained below.

Additionally, an important feature of online learning which increases satisfaction is its ability to stimulate independent learning. Independent learning occurs when learners control the process related to their learning activity (Dang, 2010). Prahtibha (2017) and Kizil (2017) affirmed that the use of computers for language learning does not only make learning ubiquitous but also it encourages self regulated learning and increases students' motivation, satisfaction and language proficiency better than classroom study. Hence, in 
this study learner satisfaction was defined based on the principles developed by Chapelle (2001) and revised in Chapelle, Jamieson \& Preiss (2005) and its facilitation for self-study.

\section{Chapelle's Criteria for Computer Assisted Language Learning (Call) Evaluation}

> Language learning potential: This refers to the capacity for CALL applications to provide learners with beneficial instructions on grammar and vocabulary skills (focus on form).

$>\quad$ Learner fit: This means how usable is the resource to suit the learning styles and needs of learners with diverse range of abilities. This includes how learners can plan, and monitor their learning to check understanding and progress.

$>$ Meaning focus: This refers to the extent to which learners' attention are drawn to meaning which can have an impact in learners' interest, motivation and achievement.

$>$ Authenticity: This means the relationship between language and learning activities in the resource to promote effective involvement in social practice. It also includes its capacity to build on learner's prior knowledge and promote active and self-regulated learning.

$>$ Positive impact: This is the extent to which the activities in a computer learning application positively affects learners speaking, listening, reading and writing skills.

> Practicality: This refers to the adequacy of the activities in the resource is to support language learning.

\section{RELATED STUDIES ON TELL ME MORE}

As regards Tell Me More, though there are a number of studies, none has explicitly investigated learners' satisfaction. These studies have stressed how learners benefitted linguistically and communicatively in the target language. For example, the study by Yunus, Hasim, Embi and Lubis (2010), on the utilization of Tell Me More in a Malaysian University revealed that both the lecturers and students participants were pleased with how the program improve their communication, grammatical and lexical skills. Additionally, the users reported that the authentic materials and activities smoothened their learning. The lecturers on the other hand indicated that the courseware was useful for blended learning and it agreed with the students on its suitability, ease of use and usefulness. Although the study further evaluated the utilization of TMM based on the principles of Chapelle (2001), it did not focus on learners' satisfaction with the program based on the principles.

Nielson (2011) studied the use of Rosetta Stone and Tell Me More by adult learners to improve their proficiency in Spanish, Arabic and Chinese showed how learners interacted in the modification of the structure to negotiate meaning. Like the study above, it showed that both programs were easy to access to be used to improve diverse range of skills. However, because of the recurring technological problems and inadequate support for their self-study with the program, the learners lost interest in using the program. This resulted in instructors having little insight into the effectiveness of the programs. What is clear from this study is its report on inadequate support and learners lost interest in using the program. These findings suggest that there may factors to account for learners' use and satisfaction with the program to negotiate meaning.

Moreover, Espinoza (2013) research into the perceptions of 75 teachers who used Tell Me More for six months indicated that the teachers had a moderate to low satisfaction with the usefulness, interest and effectiveness to improve their communication skills. However, the users experienced an average improvement with some communication and linguistic skills like oral and written comprehension, vocabulary, grammar or pronunciation. In addition, the users were dissatisfied and criticized the voice detection function in the program. The clear focus of this study on learners' perception and the findings of their dissatisfaction further widens the gap and strengthens the call for a study on learners' satisfaction. 
Furthermore, Perez (2014) investigation into Philippine university users who were paramedical and medical students revealed that the Tell Me More effectively enhanced the students' communication skills. In addition, there were no significant difference in students' perceptions concerning the effectiveness of Tell Me More. Interestingly, the student reported to have encountered no difficulties with the program. This study further confirms the inadequacy of research on learners' satisfaction with Tell Me More.

A study by Kuama and Intharaksa (2016) nearly covered every aspect of research on the asynchronous learning program Tell Me More, however, it did not examine the aspect of learners' satisfaction with the program in isolation. It examined learners' perceptions of problems, learning strategies, and the designs and content of English learning tasks in an online course that had TMM as the online course component. The findings revealed learners discontent with the program not only because of the problems they encountered but also they were not self-motivated to use the program. However, the learners perceived that learning tasks in the online course and the Tell Me More program were suitable for their language proficiency.

Clearly, some specific factors that accounts for learners' satisfaction could not be adequately inferred from the studies reviewed above. More so, the studies did not investigate learners' satisfaction with TMM based on a specific framework. Whereas many researches on the use of Tell Me More have focused on perceptions, effectiveness and the utilization of TMM, studies are yet to be conducted on specific factors that influences learners' satisfaction. In addition, studies have not yet been conducted in countries where the vast majority of students learn English language in a setting where contact with the target language is inadequate. Learners in such a setting perceive language learning differently from those who study in areas where research has already been conducted. This has motivated the call for research on learners' satisfaction in this context.

Therefore, based on the criteria developed and explained above by Chapelle, Jamieson \& Preiss, (2005), this study aimed at investigating learners' satisfaction with the Tell Me More program through both quantitative and qualitative methodologies.

The research questions for the study were as follows:

$>$ What were learners' satisfaction in using Tell Me More for English language study?

$>$ To what extent were learners satisfied with Tell Me More as a self-study program?

$>$ What factors accounted most for learners' satisfaction with TMM?

\section{METHODOLOGY}

\section{Setting}

The setting for this research was a university in the south of Thailand. All students were required to use the Tell Me More program as a part of an English language course for the 2015 academic year. The students had to take a placement test incorporated in the program to know their proficiency level. To determine their progress and level of achievement, they did a progress and achievement tests in the middle and at the end of the semester respectively. The used the TMM program for specific hours based on their levels of proficiency in the placement test. The beginners were required to utilize the program for $\mathbf{5 0}$ hours. The intermediate group spent between $\mathbf{3 0}$ to $\mathbf{4 0}$ hours, while the advanced group spent 20 hours.

\section{Population and Sample}

The population for this study were 2,137 Thai university students. These students completed the full TMM course in the 2015 Academic Year. The course had placement, progress and achievement tests as its components. Using the technique by Krejcie \& Morgan, (1970) 350 samples were selected for the study. $26 \%$ of the students were males 
whiles $74 \%$ were females. The students were from the following faculties: Natural resources (55\%); Economics (23\%); Engineering (5\%); Science (7\%) and Thai Traditional medicine $(10 \%)$.

\section{Instruments and Data Collection}

This study used mixed research methodologies. A questionnaire and semi structured focus group interview were used as the data collection instruments. The questionnaire was used to collect, analyze and interpret learners' satisfaction with the Tell Me More program. The rationale for the use of focus group discussion was to have depth of understanding about learners' satisfaction. According to Creswell (2009), mixed method strategy allows researchers to simultaneously collect data, concurrently analyze the data to confirm findings in relation to the impressions and opinions of respondents of a study.

\section{Questionnaire}

The questionnaire consisted of three parts. The first part elicited respondents' gender, faculty and phone number or email. The second part asked respondents for their perceptions of aspects in the program they considered useful. The purpose of this was to find out specific aspects of the program learners felt satisfied. Additionally, this was done to complement and make concrete the findings from the third part of the questionnaire. The third part had items that measured learners' satisfaction with TMM based on Chapelle, Jamieson \& Preiss (2005) principles for the evaluation CALL programs.

The Likert scales for the questionnaire ranged from (1) strongly disagree to (5) strongly agree. The measurement of interval between the scales was constant along the continuum (Appendix 1). This was done to find the relationship between the items and the scales for an adequate reliability estimate. A bilingual translator translated the questionnaire, originally written in English, into Thai. Three panel of experts in educational technology further scrutinized both versions of the instruments. Appropriate changes were effected in both the English and Thai versions of the questionnaire to make them compactible.

\section{Piloting}

The questionnaire was piloted among $\mathbf{5 0}$ students who used the Tell Me More program during the summer of the Academic Year 2015. The list of students' names, faculties and numbers was obtained from the administrator for piloting. The questionnaires were distributed to the respondents at their various faculties. Eighty (80) questionnaires were distributed for piloting. Among the eighty questionnaires distributed, 58 were returned for analysis. However, eight questionnaires were badly filled and were not included in the data for analysis. There were 34 items divided into five constructs including one open-ended questions in the questionnaire. The items in the questionnaires were analyzed for its reliability using Cronbach alpha with an SPSS program. The reliability of the questionnaire was .73, which was considered an adequate value for internal reliability of a scale (DeVellis, 2003).

The final questionnaires consisted of 14 items. It was distributed at the end of the first semester in 2016 Academic Year. For a high return rate, the researcher used two methods for data collection. The first method was during class sessions. The researcher sought permission from lecturers from the selected faculties for the distribution and collection of questionnaires to be done at different class hours. Others were distributed through snowball technique. Here, the researcher found some subjects for the study, gave them copies of the questionnaire for onward distribution to students who used the program in the 2015 academic year. The respondents' students' I. D's were checked to confirm whether they used the program during the said academic year. It took two weeks for the entire data collection process. All the $\mathbf{3 5 0}$ questionnaires were returned. However, $\mathbf{1 0}$ questionnaires were either badly filled or incompletely and were excluded from the final analysis. 


\section{Focus Group Interview}

A semi structured focus group interview was conducted in order to simultaneously analyze the data, confirm the findings in relation to the impressions and opinions of respondents of this study. The semi structure focus group interview was structured to have an in-depth investigation into specific aspects of the program that determined learners' satisfaction or discontent with the TMM program.

It was guided by learners' perception of the usefulness of TMM and the principles of Chapelle, Jamieson \& Preiss (2005): Language learning potential, Learner fit, Meaning focus, Authenticity, Positive impact and Practicality. The interview guide consisted of 8 open ended items with sub questions under some items. Participants for the semi structured focus group interview were invited by phone calls and classroom announcement at the selected faculties that took part in the survey. For the phone calls, the participants were randomly selected based on the responses in the questionnaire. Ten (10) students showed up for the interview. The interview was conducted in Thai by the help of a proficient bilingual moderator. The moderator, who was already knowledgeable about the research, was further trained on specific questions to ask, how to keep the discussion going by asking follow up questions and how to make the participants feel comfortable throughout the process.

He asked permission for the interview to be video recorded for transcription and translation purposes. The participants were assured of the confidentiality of their response. This made them certain that their response will not be revealed under any circumstances. The moderator proceeded to interview participant by following a guide. The moderator appreciated the corporation of participants at the end of the interview. It lasted between 30 to 45 minutes.

\section{Data Analysis}

Items in the questionnaire were statistically analysis with an SPSS program to find the percentages, means and standard deviations. This analysis was done because the findings would be inapplicable to other population. For the focus group interview, the bilingual expert transcribed the responses into Thai. The bilingual expert listened to and transcribed the responses again from the recorded video tape. The participants were given the pseudonyms (Participant 1 to 10 ) and their responses were written under their pseudonyms. The second transcription was done to ensure consistency in both Thai scripts. Both transcripts were compared to ensure its reliability and credibility. The bilingual expert then translated the responses into English. After that, the English version was subjected to content analysis by both the researcher and bilingual translator.

Using an inductive approach (Cresswell, 2009), the researcher analysed the transcript by selecting common patterns and themes and categorized them based on the principles for the evaluation of CALL programs (Chapelle, Jamieson \& Preiss, 2005). The themes were triangulated with responses from the survey to identify common patterns emanated from both analysis. Both of the findings were further concurrently analyzed and subjected to thematic categorization based on Chapelle, Jamieson \& Preiss, (2005) principles for the evaluation of CALL programs. This parallel analysis of the data aimed at deepening understanding on the factors that influenced learners' satisfaction with the Tell Me More program. Additionally, it complemented the limited amount of information that was elicited from the questionnaire for richer and more precise inferences. 


\section{FINDINGS}

The findings below give both the quantitative and qualitative analysis of learners' satisfaction. The tables report the means and standard deviation while the figures report the percentages. The results are organized below:

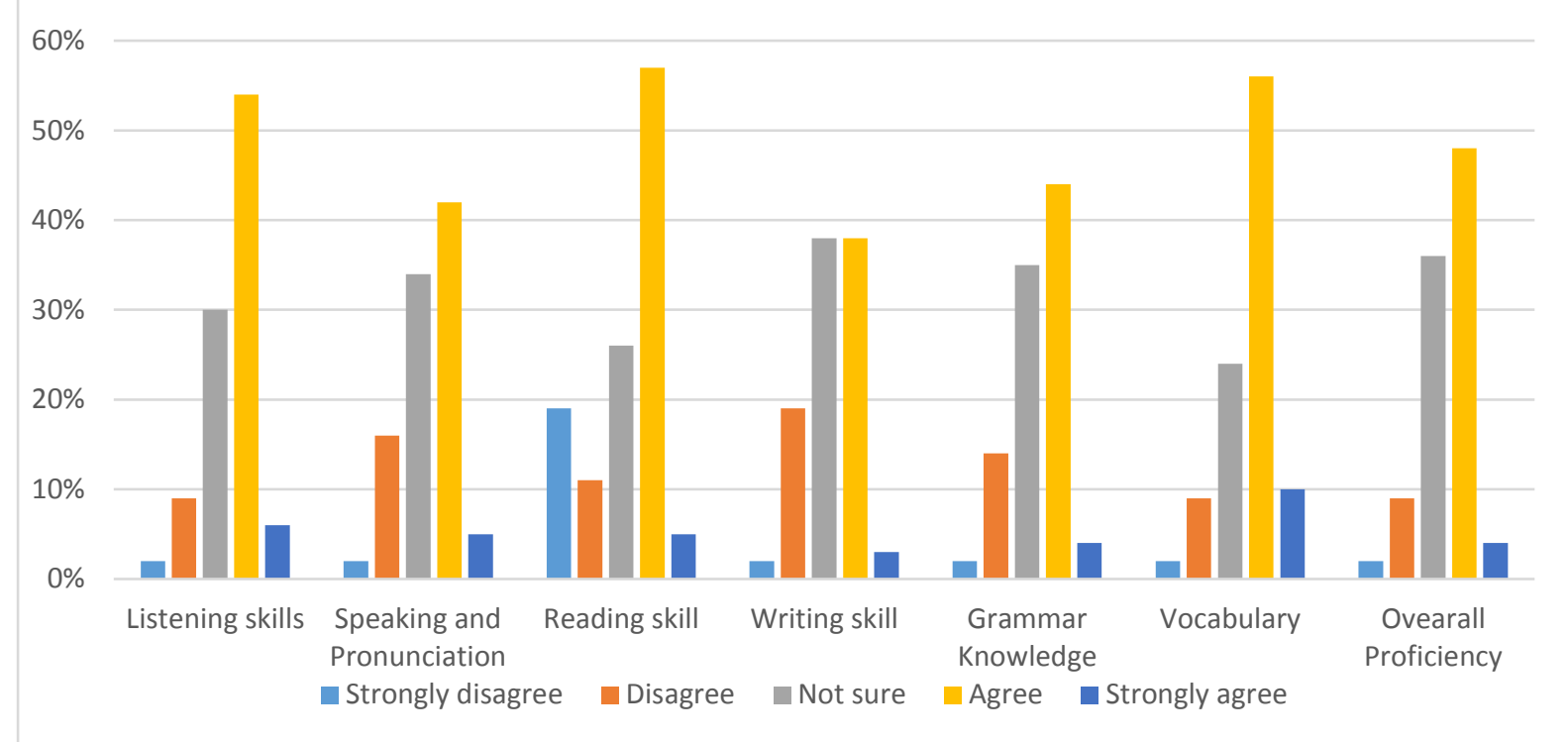

Figure 1. Percentages of the perceived usefulness of TMM

In the Figure $1.54 \%$ and $6 \%$ of the participants agreed and strongly agreed that the program was useful for practicing and improving their listening skills. $30 \%$ of the participants were however not sure whether the program was useful for listening while $9 \%$ of the participants disagreed while $2 \%$ strongly disagreed with the program's usefulness for listening. This item had the second highest mean $(x=3.53$, Table 1 .) because of inadequate opportunities learners get to interact in English in their society. Learners only had the opportunity to use English in some few English courses. Hence, listening to the activities in the program increased the avenues for coming into contact with English.

As regards its usefulness for practicing speaking and pronunciation, a similar proportion of $42 \%$ and $5 \%$ of the participants agreed and strongly agreed that the program was useful for that purpose. $34 \%$ were not sure whether the program effectively served that purpose. On the other hand, $16 \%$ and $2 \%$ disagreed and strongly disagreed that the program was not useful for practicing either speaking or pronunciation. Though this item had the second lowest moderate mean ( $x^{-}=3.31$, Table 1.), it excited learners because it gave learners the chance to at least mimic words and phrases which they may by shy or not confident enough to say under normal circumstances. However, learners could not engage in a conversation with the program except to mimic the words and phrases.

In the case of reading, whereas $\mathbf{5 7 \%}$ and $\mathbf{5 \%}$ agreed and strongly agreed to TMM's usefulness for reading, $26 \%$ were not sure while $11 \%$ and $2 \%$ disagreed and strongly disagreed with its usefulness for reading. The mean for this item was the third highest $\left(x^{-}=3.52\right.$, Table 1.) This finding shows how learners could identify word, phrases and finally string them into sentences and read them out for self-satisfaction. This in some way boasted learners' confidence to read out sentences on their own without any assistance from an instructor. 
The item on writing recorded the lowest mean $\left(x^{-}=3.21\right.$, Table 1.). The percentages showed that whereas $38 \%$ and $3 \%$ agreed and strongly agreed to its usefulness for writing, $38 \%$ were not sure. $19 \%$ and $2 \%$ disagreed with the program's usefulness for writing. This confirmed learners' dissatisfaction with the writing aspect. One factor that could account for this is learners' inability to apply the grammatical knowledge to form appropriate sentences.

As regards grammar knowledge, $44 \%$ and $4 \%$ of the participants agreed and strongly agreed with the program's usefulness for enhancing their grammar knowledge. However, $35 \%$ were not sure about that while $14 \%$ and $2 \%$ disagreed and strongly disagreed. The mean for this item was $\bar{x}=3.34$ (Table 1). Though this finding may suggests learners' preference for grammar aspect, the high rate of uncertainty may mean that learners could not appropriately apply the grammar knowledge to other skills they learned with the program. Hence, the writing part had the lowest because learners may not have found the relationship between those two skills in the program.

Fifty-six $(56 \%)$ and ten $(10 \%)$ of the participants indicated that the program was very useful for vocabulary learning but $24 \%$ were not sure, leaving only a $9 \%$ and $2 \%$ to disagreed and strongly disagreed with the program's usefulness for improving vocabulary learning. The mean for this item which was the highest $\left(x^{-}=3.70\right.$, Table 1 .) shows that the program has enough content for vocabulary learning. The activities for vocabulary learning are structured around activities such as crosswords, dictations and gap filling. Hence, learners may have found it as an interesting way to improve their vocabulary knowledge.

Overall $48 \%$ and $4 \%$ agreed and strongly agreed that the program was useful for improving learners overall language proficiency. While $36 \%$ were not sure, $9 \%$ and $2 \%$ disagreed and strongly disagreed that with the usefulness of the program to improve overall English language proficiency. The mean and standard deviation for this item was $\bar{x}=3.42$ (Table 1.).

Table 1. Items investigating learners' satisfaction with specific aspects of TMM (Means and standard deviations)

\begin{tabular}{|c|c|c|c|}
\hline & I am satisfied with TMM because & $\bar{X}$ & SD \\
\hline 1. & TMM helps me improve my listening skill. & 3.53 & .803 \\
\hline 2. & $\begin{array}{l}\text { TMM helps me improve my speaking and } \\
\text { pronunciation skill. }\end{array}$ & 3.31 & 30 \\
\hline 3. & TMM helps me improve my reading skill. & 3.52 & .829 \\
\hline 4. & TMM help & 3.21 & .859 \\
\hline 5. & $\begin{array}{l}\text { TMM helps me improve my grammar } \\
\text { knowledge. }\end{array}$ & 3.34 & .859 \\
\hline 6. & $\begin{array}{l}\text { The activities in TMM are useful for vocabulary } \\
\text { learning. }\end{array}$ & 3.70 & 1.769 \\
\hline 7. & $\begin{array}{l}\text { I have improved my overall English language } \\
\text { proficiency }\end{array}$ & 3.42 & .822 \\
\hline
\end{tabular}


In Figure 2. below, 54\% and $9 \%$ agreed and strongly agreed respectively that the language learning activities in the program was beneficial. While $8 \%$ and $2 \%$ disagreed and strongly disagreed, $\mathbf{2 7} \%$ were not sure whether the program was beneficial. Even though this item recorded one of the highest mean $(\bar{x}=3.58$, Table 2 .), it was slightly above moderate. This finding suggests that the learners were moderately satisfied with the Tell Me More program. This confirms the moderate perception learners had of grammar and writing parts Table 1).

It also means that the content for learning reading, grammar and writing may not have challenged them beyond their current level of knowledge. Participant 1 said this during the focus group interview:

The grammar, writing and the vocabulary activities are helpful but getting more activities in the program where I can use this to improve $m y$ speaking skills will be much better.

As regards learning style, $47 \%$ and $3 \%$ agreed and strongly agreed that the program fits their learning style. While a sizable number of participants $32 \%$ were not sure, $14 \%$ and $4 \%$ disagreed and strongly disagreed that the program suited their learning style. While less the half of the respondents feel the program fits their learning style, $32 \%$ were not sure. While some less than $\mathbf{5 0 \%}$ (for those who agree and strongly agree) may prefer full online learning environment, others may prefer the blended mode or even the traditional way of learning. This divide between the response on learning styles and preferences may suggest that learners may not be fully used to learning in a full online environment. The moderate mean score $(\bar{x}=3.32$, Table 2 .) which was one of the lowest confirms this.

Participant 3 also revealed this:

I enjoyed using the program because I like to learn online so that I can chose the lessons I want to study on my own. It is flexible to use.

Participant 7 said:

If I have my own way, I will like to learn with a teacher in class. It is natural and flexible. $I$ can ask the teacher questions when $I$ do not understand anything. Learning with a computer is not my style.

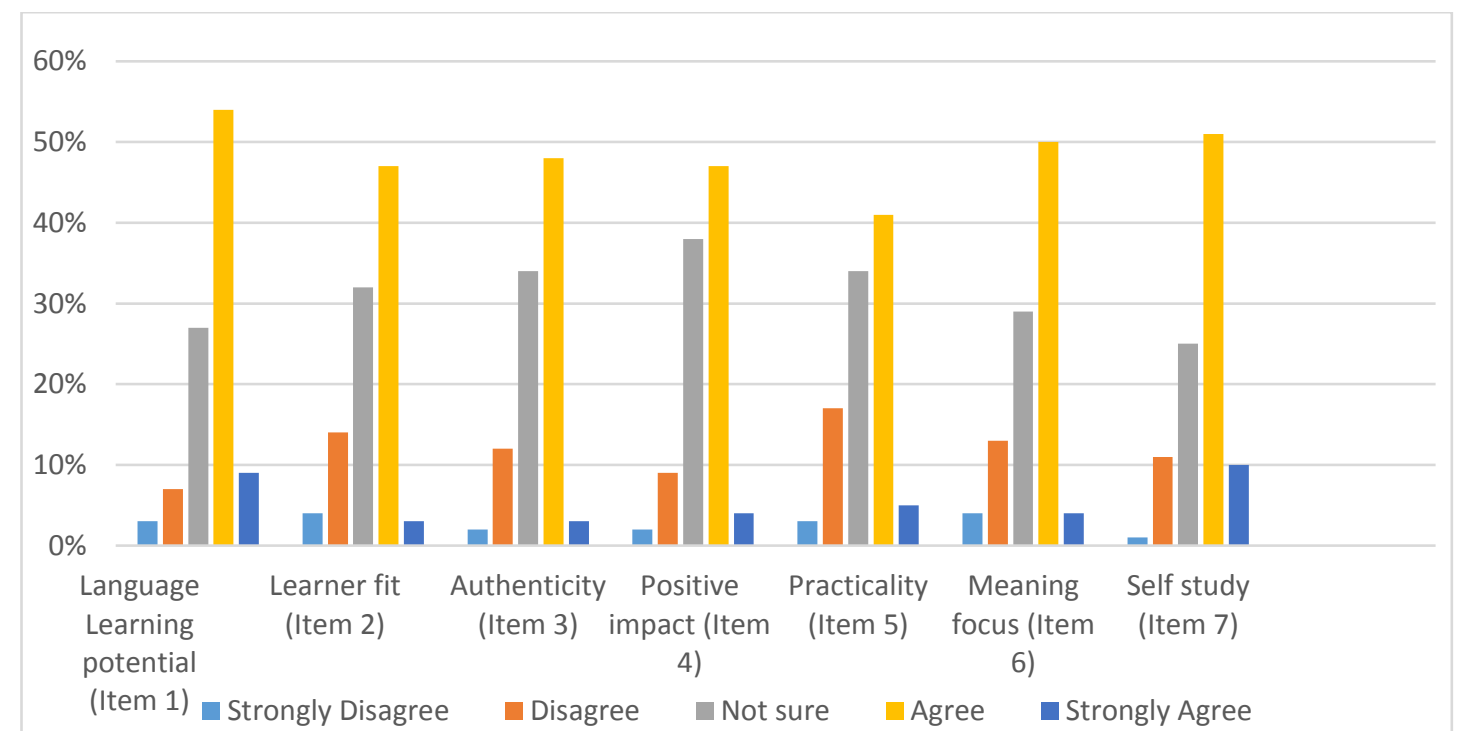

Figure 2. Percentages of learners' satisfaction with Tell Me More classified according to Chapelle, Jamieson \& Preiss, (2005). 
A little over half of the respondents, $48 \%$ and $4 \%$ agreed and strongly agreed that the activities in the program was relevant to their daily life activities. $12 \%$ and $2 \%$ expressed dissatisfaction by disagreeing and strongly disagreeing that the topics and situations in the program were helpful. $34 \%$ were not sure. Like learners' satisfaction with the TMM fit for their learning styles, there is also divide in the response on the relevance of the program to their daily life. For 52\% to agree and strongly agree and for $34 \%$ and $14 \%$ remain either undecided or disagree and strongly disagree with the content of the program mean that TMM may not be fully equipped to cater for the diverse interest of learners. The mean score was moderate ( $\bar{x}=3.39$, Table 2.). The comment of participant 2 confirms this:

Though the topics and situations could be used in my daily life, though some of them are repetitive and it makes it boring to use. There should be varieties of relevant tasks in the program to make it more useful.

Moreover, $47 \%$ and $4 \%$ were satisfied with the program because the English suited their proficiency level. $9 \%$ and $2 \%$ disagreed and strongly disagreed that the level of English suited their level of proficiency while $38 \%$ were not sure. Learners' ability to select their level of proficiency in the program could account for why half of the respondents felt moderately satisfied with the program. On the other hand, the activities may have been neither difficult nor easy for the learners for learners of different proficiency levels. That could account for why $38 \%$ remained unsure whether the program was at their appropriate level of proficiency. This mean score for this item was moderate $(\bar{x}=3.39$, Table 2.). Participant 9 made the statement below during the interview:

For me, the program is below my proficiency level even at the advanced level. Therefore, $I$ think the program is not suitable for students of higher proficiency level like me because most of the content is easy for me.

Even though $41 \%$ and $5 \%$ agreed and strongly agreed that TMM had enough content to learn English, $34 \%$ remained undecided. $17 \%$ and $4 \%$ of the participants showed dissatisfaction by disagreeing and strongly disagreeing. The mean score for this item was also moderate $(\bar{x}=3.27$, Table 2 .). Like item 7 , the moderate mean score and percentage shows that the learners may not only moderately satisfied with the linguistic (writing and grammar) but also the communicative aspects (speaking, pronunciation, listening). This may have accounted for the moderate satisfaction. The excerpts from participants 5 and 3 respectively below affirms this statistical finding:

I like the TMM program but the listening and speaking activities though interesting is not enough. It could be improved so that $I$ can relate to it better. For the vocabulary, I get enough practice but for the reading $I$ sometimes find it difficult to understand the text."

Participant 3 remarked:

Every sentence I write is wrong, but I sometimes know that my sentence is not completely wrong, only some parts but the program does not tell me which part and the grammar explanation for that is general. 
Table 2. Means and standard deviation of items investigating learners' satisfaction with TMM based on Chapelle, Jamieson \& Preiss, (2005).

\begin{tabular}{llll}
\hline Items & $\bar{X}$ & SD \\
\hline 8. & $\begin{array}{l}\text { The language learning activities in TMM are } \\
\text { beneficial. }\end{array}$ & 3.58 & .867 \\
9. TMM gives activities that fit my learning style. & 3.32 & .886 \\
10. The topics and situations in TMM are helpful in & 3.39 & .843 \\
$\begin{array}{l}\text { my daily life. } \\
\text { 11. }\end{array}$ & $\begin{array}{l}\text { The English used in TMM is suitable for my level } \\
\text { of proficiency. }\end{array}$ & 3.39 & .818 \\
12. $\begin{array}{l}\text { TMM program gives enough content to help me } \\
\text { learn English. }\end{array}$ & 3.27 & .914 \\
13. The topics and situations in TMM are & 3.36 & .923 \\
$\begin{array}{l}\text { interesting. } \\
\text { 14. I can use TMM to learn English on my own. }\end{array}$ & 3.58 & 1.331 \\
\hline
\end{tabular}

Furthermore, $50 \%$ and $4 \%$ agreed and strongly agreed that the program had interesting lessons. While $29 \%$ were not sure about interesting nature of the topics and situations were, $13 \%$ and $4 \%$ disagreed and strongly disagreed. This item also recorded a moderate mean of $(\bar{x}=3.36$, Table 2. $)$. This means that while some aspects of the program may excite learners, other aspects may be boring and irrelevant for the learners. Additionally, learner content interaction that makes the activities interesting and practical may be limited. Partcipant 10 said:

I like the speech recognition, it helps me imitate words and phrases comparable to the native speaker but it would be better if I can engage in a conversation with the program.

Participant 3 again stated:

I think some activities in the program like the crossword are too easy, repetitive and sometime boring. The writing is sometimes complicated. Every sentence $I$ write is wrong.

Finally, $50 \%$ and $10 \%$ of the participants agreed and strongly agreed that they could learn independently with the program. $25 \%$ remained undecided while $12 \%$ and $3 \%$ disagreed and strongly disagreed with the capacity of the program to become autonomous users. This item recorded the highest satisfaction ( $\bar{x}=3.58$, Table 2.) though it was moderate. The highest but moderate satisfaction may due to learners' ability to access and us the program anytime and place of their convenience without the interference of instructors. Despite the freedom of access for self-study, some respondents were unsure about the potential of the program in that regard. This may be due to technical problems with the internet connection and browser. The program could only be access with internet explorer. Participant 4 also retorted:

The Tell Me More program gives me another interesting way of learning English. I can choose and plan what ways to use to understand the activities since $I$ cannot always follow the lessons in class. Sometimes, when I want to practice my English by revising what I have been taught in class $I$ use the program.

Participant 6 said:

I like to use the program to study English on my own but sometime the poor internet connection and limited browser option make it frustrating to use. 


\section{DISCUSSIONS}

The discussion section has been categorized according to research questions. First, it discusses learners' satisfaction with TMM as a self-study tool. The discussion of the factors that contributed to learners' satisfaction, which have been organized according to Chapelle, Jamieson \& Preiss, (2005) principles follow suit.

What Are Learners' Satisfaction with TMM and to What Extent are They Satisfied with TMM as a Self-Study Tool?

Specific aspects of the program that satisfied learners the most were vocabulary, listening and reading parts respectively. Even though they were at a moderate level, they ranked the highest among the items (Table 1.). The enormous amount of vocabulary in the program structured around crosswords, dictation and gap filling which the learners revealed during the focus group interview could explain learners' satisfaction with the vocabulary activities. The extra avenue the listening activities created for the learners who had limited opportunities to improve their listening skills could account for why this item was ranked the second highest. Vocabulary plays an important role in learning how to read. As learners begin to read, they link the vocabulary they have learned to the text they read, this eventually influence their listening and speaking skill (Lee, 2016; Liaw \& English, 2017). Based on this, it comes as no surprise that reading part came third in succession. However, inadequate instant feedback, limited interactions and little connection among the speaking, pronunciation, grammar and writing aspects may have also accounted for a moderate but low satisfaction with these aspects of the program (Table 1.).

The extent of learners satisfaction with TMM as a self-study tool though had the highest mean score, it was at a moderate level (Table 2, Item 14, $x=3.58$ ). This means that despite the flexibility of access and ability to self-pace learning learners' satisfaction was not at a high level. As revealed in the interview, this suggests that learners were constrained by space and location in terms of poor or unavailability of internet and limited browser option to access the program. This finding confirms the study on Rosetta Stone and Tell Me More by Nielson (2011) where technological problems and inadequate support led to the loss of interest in using the programs. Additionally, the responses from the interview suggested that the learners might have needed help that could not be instantly accessed. Hence, the learners may prefer a blended form of online learning to a full online course or face-to-face classroom lessons. The finding revealed in this study is similar to those conducted in previous studies in the field of online learning (Arbaugh \& Duray, 2002; Sukseemuang, 2009).

Despite the moderate satisfaction, the learners valued the opportunity to self-pace their learning to balance the learning of the skill they desire to improve. They also appreciated knowing their progress while using the program. In sum, the results suggest that to some extent TMM enhances autonomous learning by giving leaners the opportunity to choose what to learn, access the program at any time and place of their convenience and assess their progress at the completion of a task.

What Factors Accounted Most For Learners' Satisfaction with TMM?

Language Learning Potential

The learners expressed moderate satisfaction with the potential of the program to enhance their language ability. The interview further confirmed the participants' moderate to high satisfaction with the following linguistic aspects: vocabulary, grammar and writing respectively (Table 1.). This shows the potential of the program to improve users' linguistic competence. This finding confirms Thai learners' inclination to linguistics contents of a lesson rather that communicative aspects that allow learners to express their thoughts and feelings (Chumchaiyo, 2002 as cited in Phaisuwan, 2006). This finding is more in line with Espinoza (2013) study on TMM but partially echoes Yunus et al., (2010) research on the evaluation of Tell Me More among Malaysian users. Whereas learners in this study felt moderately satisfied with the program's potential for reading, vocabulary, grammar and 
writing, the participants in Yunus et al., (2010) though highly satisfied, found these aspects of the program less interactive.

\section{Learner Fit}

As regards learners' satisfaction with the program's suitability for their learning styles, preferences and needs based on their levels of proficiency, the responses from the survey and focus group interviews revealed a mixed reaction. This could mean that the content in the program may not be adequately mixed to appeal to the needs of learners. Additionally, some learners may not prefer this mode of learning styles. While some respondents may prefer the full online learning mode, others may opt for the blended or traditional mode of learning English. This finding confirms the conclusion drawn in the study by Callaway (2012) and Espinoza (2013) that finding "the right mix" of an online course design by considering learners needs, preferences and styles will increase learners' satisfaction. Additionally, though not the direct focus of the study, this finding supports Bollinger and Erichsen (2013) study on a hybrid and a fully online course as compared with a traditional course delivery. The findings revealed that learning styles and preferences serves as the basis for an effective online instructional design and learner satisfaction. They further reported that the English used in TMM is suitable for their level of proficiency even at the advanced level (item 11). This could be because the activities in the program has been categorized according to proficiency levels.

\section{Meaning Focus}

In relation to meaning focus, the findings revealed that the students derived meaning, got interested and motivated from activities that were structured around vocabulary, reading, speaking and listening. This was so because some were interactive and related to their daily life. This, to a larger extent supports Chapelle, Jamieson \& Preiss, (2005) definition of meaning focus as the extent to which learners' attention are drawn to meaning which can have an impact in learners' interest, motivation and achievement. According to some learners, they could retain these activities because they can relate to it. However, others reported that they could not relate to certain activities in the program such as the grammar, writing and pronunciation. This finding is in line with Yunus et al., (2010) study on the utilization of Tell Me More in which the participant reported to have fully benefitted from the listening, speaking and reading activities. It however not consistent the findings on the grammar aspect in Yunus et al., (2010) study where 98\% of the participant understood the grammar explanations in the program. This finding further echoes what Estelami (2012) found in the evaluation of a hybrid and a fully online course where students felt satisfied with the course content because of its relevance. In this study, the result indicated that students could find meaning with only some aspects of the program not the full course content. This further reinforces Wagner, Garippo, \& Lovaas, (2011) conclusion for the need for the course content to be related or adaptable to every setting to provide meaning to users. It is therefore suggested that, the linguistic contents in online learning programs could be incorporated in the communicative activities for more meaningful learning.

\section{Authenticity}

Moreover, the findings from both the survey and interview showed that the students were moderately satisfied with the authenticity of the program. This suggest that relationship between the language and communicative activities in the resource to promote effective involvement in social practice may be just enough. A significant factor that may have caused the moderate reaction for participants in this study is that the learners had little to no opportunity to use the content of the program in their EFL context. Hence, learners' inability to get the opportunity to put what they have learned from the program into use may have caused to think that the content was not fully relevant in their context. It could however be concluded that difference in research setting accounts for the different reactions as regards the authenticity of the program. The findings echoes the study by Huang et al. (2017) and Sun (2014) who posited that the quality in terms of the authenticity of the content of an online program does not only motivate and appeal to learners' interest regardless of the learning environment but it also has a relationship with learners' satisfaction. 


\section{Positive Impact}

The program had a positive impact on learners' pronunciation because they could model it after a native speaker. The speech function gave them an opportunity to imitate phrases and see their level of progress through the sound waves. The ability to mimic the utterances of the program further increased learners' satisfaction. This aspect of the program increased learners' interest and motivation. The finding is in line with Yunus et al., (2010) and Perez, (2014) study where participants did not only learn new words but listened and corrected their pronunciation. Nonetheless, learners reported interference with unrelated sounds that were sometimes recognized as correct the pronunciation function. The learners further reported in the interview that the grammar and writing parts were inadequate and speaking and listening aspects were partially useful in their daily lives. This must have caused the moderate impact on their skills. However, they appreciated the opportunity of listening to the accent of a native speaker. In sum, the result revealed that TMM was positively enhanced English language learning however, some features need to be improved to effectively support language learning.

\section{Practicality}

The findings from both the survey and interview showed that the program could moderately improve learners' linguistic and communicative competence. This finding supports Bodnar et. al, (2016) recommendation that for students to feel satisfied with an online learning program there should be adequate content to ensure active through the provision of enough linguistic and communicative activities to ensure holistic learning, engagement and interactive support for users in any learning community. However, students did not get enough of that in the program as reported in this study. The findings further show that learners may need help whenever they use the program. This finding is however not consistent with Yunus et. al, (2010) study where the students reported that they needed no help because every activity offered a lot of content, exercises and feedback that were helpful for language learning.

\section{CONCLUSIONS}

Even though moderate, the factors that accounted most for learners' satisfaction with TMM was the language learning potential and the ability to use TMM for self-tutoring. This shows that the program may be more suited for learning pre-communicative such as reading, grammar, writing and pronunciation rather than spontaneous communication skill. However, learners mixed reactions with the program's moderate appeal to their learning style, needs and preferences mean that the program needs to be improved to cater for diverse range of learning styles and needs.

Additionally, learners' moderate but satisfactory report of enjoying the pronunciation, reading, vocabulary and listening aspects signifies that learners may have found these aspects more meaningful, practical and authentic than other aspects of the program. Overall, the analysis suggested that the learners were moderately satisfied with TMM.

The moderate satisfaction learners had in using the TMM program in this study shows that language learning is far from simple especially for EFL students. Even though the TMM program was used as a supplementary tool that provided students with sophisticated interface, it could not compensate for human interaction and support which students may need for high satisfaction. This may also have accounted for the moderate level of satisfaction with the program.

Hence, the use of TMM and CALL programs aimed at supplementing the acquisition of a foreign language online should not only abide by standards that ensure effective CALL course design but also fulfill principles that give users satisfaction. In addition, opportunities for appropriate feedback and output interaction through intrapersonal communication could be considered to ensure effective online learning to increase satisfaction (Blake, 2011; Nielson, 2011 \& Nielson \& Gonzalez-Lloret, 2010). Research on 
CALL also indicates that learners may find language-learning programs satisfying and beneficial if they are guided and supported by a wide range of resources (Warschaeur \& Liaw, 2011).

In sum, this study has given an in-depth insight into factors that increases or hinder learners' satisfaction with asynchronous online learning programs. It has further enlightens institutions on other dimensions to consider when choosing online learning programs.

\section{LIMITATIONS AND FURTHER STUDIES}

This study is limited in terms of how learners' context, perceptions and interest influenced their satisfaction. Additionally, the 5-point Likert scale used in the survey accommodated neutral feeling and did not force respondents to make a specific stance on the response. This may have resulted in the moderate response for all the items. A 6-point Likert scale could be used in further studies to ensure a well-balanced response. Further studies could investigate the correlation between learners' perception and satisfaction and its effect on achievement.

\section{BIODATA and CONTACT ADDRESSES of AUTHORS}

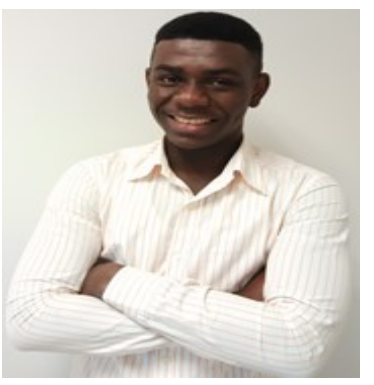

\section{George GYAMFI}

Department of Western Languages, Faculty of Humanities and Social Sciences Thaksin University, 90000, Songkhla, Thailand Phone: +66 950670579

E-mail: ggyamfi4u@gmail.com or george.g@tsu.ac.th
George GYAMFI holds a Bachelors degree in English from Kwame Nkrumah University of Science and Technology, Ghana. He earned his Masters degree in Teaching English as an International Language at Prince of Songkla University, Thailand. He worked as a teaching assistant while pursuing his MA degree. He has publications indexed in international databases. Mr. Gyamfi is currently a lecturer in English at the department of western languages, Thaksin University, Thailand. His research interest includes self-directed online learning, educational technology for teaching and learning English and curriculum design.

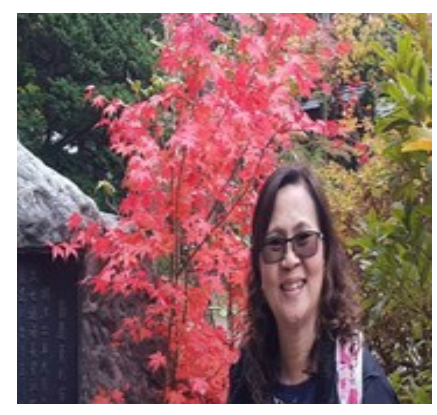

Panida SUKSEEMUANG, Ed.D. is a lecturer at the department of Languages and Linguistics, Faculty of Liberal Arts at Prince of Songkla University. She earned her Masters in Linguistics and Doctoral degree in Applied Educational Studies from Chulalongkorn University, Thailand and Oklahoma State University, USA respectively. Along with faculty duties, she serves as the assistant president for student development and engages in educational projects in different provinces in Thailand and the ASEAN region. She is interested in online learning, selfdirectedness and teaching reading.

\section{Dr. Panida SUKSEeMUANG}

Department of Languages and Linguistics, Faculty of Liberal Arts

Prince of Songkhla University, 90110, Songkhla, Thailand

Phone: +66 813687391

E-mail: pat.sukseemuang@gmail.com or phanida.s@psu.ac.th 


\section{REFERENCES}

Arbaugh, J. B., \& Duray, R. (2002). Technological and structural characteristics, student learning and satisfaction with web-based courses - An exploratory study of two online MBA programs. Management Learning, 33(3), 331-347.

Blake, R. (2011). Current Trends in Online Language Learning. Annual Review of Applied Linguistics, 31, 19-35.

Bodnar, S; Cucchiarini, C; Strik, H; \& Hout, R.V., (2016). Evaluating the motivational impact of CALL systems: current practices and future directions. Computer Assisted Language Learning 29(1), pages 186-212.

Bollinger, D.U., \& Erichsen, E.A. (2013). Student satisfaction with blended and online courses based on personality type. Canadian Journal of Learning \& Technology, 39(1), 1-23.

Callaway, S.K. (2012). Implications of online learning: Measuring student satisfaction and learning for online and traditional students. Insights to a Changing World Journal, retrieved from www.franklinpublishing.net

Creswell, J. W. (2009). Research design: qualitative, quantitative, and mixed methods approaches ( $3^{\text {rd }}$ ed.) London: Sage Publications.

Chang, Yueh-ching (2010), Discourse and Identity in Online Language Learning: A Case Study of a Community College ESL Classroom (Doctor Dissertation). Retrieved from http://escholarship.org/uc/item/7×20w17f

Chapelle, C. (2001). Computer applications in second language acquisition: Foundations for teaching, testing, and research. Cambridge: Cambridge University Press.

Chapelle, C., Jamieson, J. \& Preiss, S. (2005). Call evaluation by developers, a teacher, and students. Retrieved from https: //calico.org/a-133-CALL\%

Chen, W. L. C., \& Bagakas, J. G. (2003). Understanding the dimensions of self-exploration in web-based learning environments. Journal of Research on Technology in Education, 34(3), 364-373.

DeVellis, R. F. (2003). Scale development: Theory and applications. California: Sage Publications.

Dang, T. T. (2010). Learner autonomy in EFL studies in Vietnam: A discussion from sociocultural perspective. English Language Teaching, 3(2), 3-9.

Er, E., Ozden, M., \& Arifoglu, A. (2009). A blended e-learning environment: A model proposition for integration of asynchronous and synchronous e-learning. International Journal of Learning, 16(2), pp. 449-460.

Espinoza, B (2013). Learning English using Tell Me More: Perspectives of university teaching staff as users of the online application. Retrieved from https: / / www.researchgate.net/publication/278171803Learning English with Tell Me More Perspectives of university teaching staff as users of the online platform

Estelami, H. (2012). An exploratory study of the drivers of student satisfaction and learning experience in hybrid-online and purely online marketing courses. Marketing Education Review, 22(2), 143-155. doi:10.2753/MER10528008220204.

Harris, J., Mishra, P., \& Koehler, M. (2009). Teachers' technological pedagogical content knowledge and learning activity types: Curriculum-based technology integration reframed. Journal of Research on Technology in Education, 41(4), pp. 393-416. Retrieved from http://learnonline.canberra.edu.au/file.php/5963/TPACK_UC /pdf/harris_mishra_koehler_jrte.pdf 
Hubbard, P., \& Levy M., (2016). Theory in computer-assisted language learning research and practice from: The Routledge Handbook of Language Learning and Technology Routledge. Accessed on: 05 Sep 2017

Huang \& Wang, (2012). An Analysis of University Freshman Students' Satisfaction in Using On-line English Practice Exams. Journal of Global Business Management, 8(1). 88-97.

Huang, F.; Teo, T., \& Zhou, M. (2017). Understanding Factors Influencing English Teachers in Chinese Universities to Teach with Technology: A Case Study. New Ecology for Education - Communication X Learning, pages 119-130.

Kizil, A.S. (2017) EFL Learners in the Digital Age: An Investigation into Personal and Educational Digital Engagement. RELC Journal 49.

Kramsch, C. J. (2009). The multilingual subject: What foreign language learners say about their experience and why it matters. Oxford, UK: Oxford University Press.

Krejcie, R.V. \& Morgan, D.W. (1970). Determining Sample Size for Research Activities. Educational and Psychological Measurement, 30, 607-610.

Kuama, S. \& Intharaksa, U. (2016). University students' perceptions of an online English language course. Proceedings of ICHiss 2016: $8^{\text {th }}$ International Conference on Humanities and Social Sciences. National Defence University of Malaysia. (pp 226-336). Selangor, Malaysia.

Lee, L.W. (2016) Multisensory modalities for blending and segmenting among early readers. Computer Assisted Language Learning 29(5), pages 1019-1034.

Liaw, M.L; \& English, K (2017). Technologies for Teaching and Learning L2 Reading. The Handbook of Technology and Second Language Teaching and Learning, pages 6276.

Nielson, K. (2011). Self-Study with Language Learning Software in The Workplace: What Happens? Language Learning \& Technology Volume 15, Number 3 pp. 110-129. Retrieved December 8, 2016, from http: / /llt.msu.edu/issues/october2011/nielson.pdf.

Nielson, K., \& Gonzalez-Lloret, M. (2010). Effective online foreign language courses: Theoretical framework and practical application. EUROCALL Review, 17. Retrieved January 15, 2017, from http://www.eurocall languages.org/review/ 17/index.htmI\#nielson_gonzalez.

Norton, B., \& Williams, C. J. (2012). Digital identities, student investments and eGranary as a placed resource. Language and Education, 26(4), 315-329.

Parlak, O., \& Ziegler, N. (2017). The impact of recasts on the development of primary stress in a synchronous computer-mediated environment. Studies in Second Language Acquisition 39(2), pages 257-285

Perez, A. (2014). Effectiveness of Tell Me More in Enhancing Communication Skills. Asia Pacific Journal of Multidisciplinary Research P-ISSN 2350-7756 / E-ISSN 23508442 | Volume 2, No. 6 | December 2014.

Phaisuwan, C. (2006). A study on needs and problems of Seagate planners in using the English language to establish an ESP course. Unpublished master's research paper, Bangkok: Thammasat University, Language Institute, English for Careers.

Prensky, M. (2001),"Digital Natives, Digital Immigrants Part 1", On the Horizon, Vol. 9 Iss 5 pp. 1 - 6 http://dx.doi.org/10.1108/10748120110424816.

Prahtibha, M. (2017). Promoting Self-Learning in Developing Communication Skills of Technical Students. IRA International Journal of Education and Multidisciplinary Studies (ISSN 2455-2526), 6(1), 1-8. doi:

http://dx.doi.org/10.21013/jems.v6.n1.p1. 
Rashidi, N. \& Moghadam, M. (2014). The effect of teachers' beliefs and sense of selfefficacy on Iranian EFL learners' satisfaction and academic achievement. The Electronic Journal for English as a Second Language, 18(2), 1-23. http://www.teslej.org/wordpress/issues/volume18/ej70/ej70a3/

Rodinadze S. \& Zarbazoia K. (2012). The Advantages of Information Technology in Teaching English Language. Frontiers of Language and Teaching Vol. 3. TELL ME MORE manual self-editing in L2 Writing. Language Learning \& Technology, 17(3), 135-156.

Sukseemuang, P. (2009). Self-directedness and academic success of students enrolling in hybrid and traditional courses. Ph.D. Dissertation. Retrieved from http://gateway.proquest.com/open

Sun, S. Y. (2014). Learner perspectives on fully online language learning. Distance education, 35(1), 18-42.

Wagner, S.C., Garippo, S.J., \& Lovaas, P. (2011). A longitudinal comparison of online versus traditional instruction. MERLOT Journal of Online Learning and Teaching, 71), 68-73.

Warschauer, M and Liaw, M. (2011). Emerging Technologies for Autonomous Language Learning. Studies in Self-Access Learning Journal Vol 2, Issn 3, Pp 107-118 (2011) ISSN(s): 2185-3762.

Willis, J. (2006). Research-based strategies to ignite student learning: Memory, learning, and test taking success. Retrieved from http://www.ascd.org/publications/book/197006/chapters/Memory,_Learning, and Test Taking_Success.aspx

Wu, J. H., Tennyson, R. D., \& Hsia, T. L. (2010). A study of student satisfaction in a blended e-learning system environment. Computers and Education, 55(1), 155164. DOI: $10.1016 / \mathrm{j}$.compedu.2009.12.012

Yunus, M., Hasim, H., Embi, M. A. y Lubis, M. A. (2010). The Utilization of ICT in the Teaching and Learning of English: 'Tell Me More'. Procedia. Social and Behavioural Sciences, 9, 685-691. 


\section{APPENDICES}

\section{Appendix 1}

Interpretation for 5 item Likert scale for Learners' Satisfaction

\begin{tabular}{|l|l|l|}
\hline Interpretation & Satisfaction & Mean range \\
\hline Very low & Strongly disagree & 1.00 to 1.80 \\
\hline Low & Disagree & 1.81 to 2.60 \\
\hline Medium & N/A & 2.61 to 3.40 \\
\hline High & Agree & $\mathbf{3 . 4 1}$ to 4.20 \\
\hline Very high & Strongly agree & 4.21 to 5.00 \\
\hline
\end{tabular}

\section{Appendix 2}

Interview Guide

1. How useful was TMM for you in learning English. Why?

2. In what ways did TMM help improve your

3. Reading. b. Listening. c. Speaking/Pronunciation. d. Writing skill. e. Grammar and vocabulary knowledge.

4. Which of the skills and knowledge improved were you satisfied with and why?

5. How were the skills and knowledge learned from the program important for your daily life?

a. Were there any aspects in the program that were irrelevant to you?

b. Could you give specific examples?

6. Were you satisfied with the activities in the program? Why?

a. How meaningful were the activities?

b. Could you mention some activities?

7. Was TMM suitable for you in learning English? Why?

a. Did it fit your learning style? How?

b. How about your level of proficiency? Why?

8. Was Tell Me More an appropriate program for self-study? Why? How?

a. Were you satisfied with using it for self-study? Why?

b. How did they satisfy your practical needs?

9. In general, to what extent were you satisfied or dissatisfied with the TMM program? 